Çukurova Üniversitesi Mühendislik Mimarlık Fakültesi Dergisi, 32(1), ss. 73-80, Mart 2017

Çukurova University Journal of the Faculty of Engineering and Architecture, 32(1), pp. 73-80, March 2017

\title{
Cer Makinasında Ekartman Ayarlarının İplik Kalite Özelliklerine Etkisinin İncelenmesi
}

\author{
Belkis ZERVENT ÜNAL ${ }^{* 1}$, Soner VURKIR ${ }^{1}$ \\ ${ }^{1}$ Çukurova Üniversitesi, Mühendislik Mimarlık Fakültesi, Tekstil Mühendisliği Bölümü, Adana
}

Geliş tarihi: 04.01.2017

Kabul tarihi: 14.03 .2017

\section{$\ddot{\mathbf{O z}}$}

Çalışma kapsamında, birinci ve ikinci cer pasajı aşamalarında cer makinası ekartman ayarlarındaki değişimin seçilmiş iplik özelliklerine etkisinin belirlenmesi amaçlanmıştır. Bu amaçla her iki pasaj için iki farklı ekartman mesafesi ayarı seçilerek cer şeridi üretimi gerçekleştirilmiş ve bu şeritler sabit üretim parametreleriyle iplik haline getirilmiştir. Ardından ipliklerin tüylülük, düzgünsüzlük ve mukavemet değerleri test edilmiş ve ekartman mesafesindeki artışın üç iplik özelliğini de olumsuz etkilediği görülmüştür. $\mathrm{Bu}$ durumda çalışmada numune olarak seçilen Şanlıurfa GAP pamuğu için daha kısa ekartman mesafesinin iplik kalite parametreleri açısından daha olumlu sonuçlar doğurduğu belirlenmiştir.

Anahtar Kelimeler: Cer makinası, Ekartman ayarları, Mukavemet, Düzgünsüzlük, Tüylülük

\section{Investigation of Effect of Roller Setting on Yarn Quality Properties in Draw Frame}

\begin{abstract}
In the scope of the study, it was aimed to determine the effect of the variation of the roller setting on the selected yarn properties in the first and second passage draw frame stages. For this purpose, two different draft distances were chosen for both passages and draw frame strip was produced. Then, these strips were made into yarn with constant production parameters. The hairiness, unevenness and strength properties of the yarns were tested with standard method. As a result, it was observed that increasing the draft distance affects negatively the selected three yarn properties. In this case, it has been determined that the shorter draft distance has more positive results in terms of yarn quality parameters for Şanliurfa GAP cotton selected as the sample in the study.
\end{abstract}

Keywords: Draw frame, Roller setting, Strength, Unevenness, Hairiness

\footnotetext{
*Sorumlu yazar (Corresponding author): Belk1s ZERVENT ÜNAL, belzer@cu.edu.tr
} 


\section{GíRiş}

Sadece ticari açıdan bakıldığında cer makinası, üretim hattındaki diğer makinalara göre daha az önem taşımaktadır. Genellikle iplik üretim maliyetlerinin \%3'den daha azını oluşturmaktadır. Ancak iplik düzgünsüzlüğü başta olmak üzere iplik mukavemeti ve uzaması gibi iplik kalite özellikleri üzerine etkisi oldukça büyüktür.

Cer makinası, iplik eğirme prosesi içerisinde kütle değişimlerinin düzeltilmesi için dublaj ve regülenin uygulanabileceği son işlem basamağıdır [1]. Burada giderilemeyen hatalar ipliğe ve dolayısıyla örme/dokuma kumaşa yansıyacaktır. Cer makinasının iplik düzgünsüzlüğünü önemli ölçüde etkilemesinin iki ana nedeni vardır. Birincisi, kısa lif iplikçiliğinde makinaların diziliminde, cer makinası hataların giderilmesi için son düzeltme noktasıdır. Cer makinasından çıkan üründeki eksiklikler sadece ipliğe geçmekle kalmaz, bu yetersizlikler cer makinasını takiben çekim etkileri ile fiilen de pekiştirilir. Dolayısı ile iplik hiç bir zaman cer şeridinden daha iyi olamaz. İkinci olarak, cer makinasında meydana gelen bir hata tüm prosesi önemli oranda etkiler. Yüksek performanslı cer makinaları çok yüksek hızlarda şerit üretmektedir. Hatayı saptamadan önce, geçen zaman içinde çok büyük miktarda hatalı şerit üretilecektir. Bu nedenle her modern kısa lif iplik işletmesi için regüleli cer makinaları kaçınılmaz hale gelmiştir.

İplikhanedeki tüm bölümler arasında, çekim bölümünün, ekonomik olarak tasarruf etmek için en uygunsuz yer olduğu son derece açıktır. Cer işleminde kaliteye etki eden faktörler pasaj sayısı, şerit düzgünsüzlüğü, uygulanan dublaj sayısı, regüle işleminin ilk veya son pasajda yapılması, karde/penye besleme, şerit ağırlıkları ve çekimler ile yabancı madde ve kısa lif miktarıdır [1].

\section{Cer makinasının görevleri}

1. Düzgünleştirme:

Cer makinasının temel görevlerinden birisi, kısa, orta ve özellikle uzun periyotlu düzgünsüzlükleri iyileştirmektir. Cer makinasına beslenen tarak şeritleri pratikte tolore edilemeyecek bir düzgünsüzlüğe sahiptir ve bunların giderilmesi gerekmektedir.

\section{Paralelleştirme:}

İplik özelliklerinden mukavemet için optimum bir değer elde etmek amacıyla, elyaf demeti içinde liflerin paralel olarak düzenlenmesi gerekir. Bu paralel düzenlemeyi oluşturmak esas olarak cer makinasının görevidir. Cer makinası bu görevi çekim vasıtasıyla gerçekleştirir, çünkü her çekim kademesi liflerin düzleşmesine yol açar.

\section{Karıștırma:}

Dublajlama (katlama) aracılığı ile (en az iki - en fazla sekiz) bantları çapraz olarak birleştirerek homojen bir bant elde etmek amaçlanmaktadır. Dublaj, karıştırma ile hammadde varyasyonlarını da bir dereceye kadar kompanse eder. Bu sonuçtan özellikle pamuk/sentetik veya sentetik/sentetik karışım ipliklerinin üretiminde yararlanılır. Cer makinalarında ayrı komponentlerin dozajlanması çok basit bir şekilde makinaya giren şerit sayılarının seçimi ile yapılabilir. Örneğin 67:33 bir karışım elde etmek için, bir materyalden dört şerit ve diğerinden iki şerit cer makinasına beslenir. Ancak bu şeritlerin aynı numarada olması gerekmektedir [2].

\section{Cer makinasında çekim}

Çekim işlemi; lifleri çekerek inceltmek, birbirine paralel hâle getirmek ve lifin doğal yapısından ileri gelen uçlarındaki kancaları açmak amacıyla yapılmaktadır. Çekim tertibatları 3 veya 4 silindir çiftinden oluşur (Şekil 1).

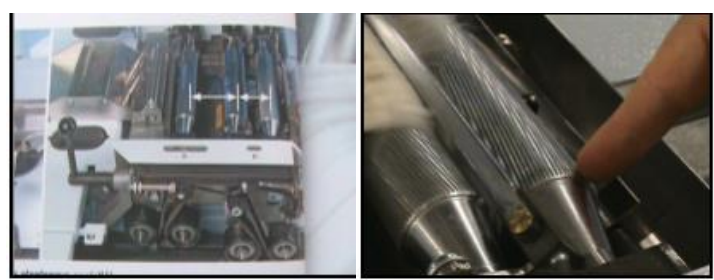

Şekil 1. Çekim silindirleri [3]

Çekim; öndeki silindirin arkadaki silindirden daha hızlı dönmesi anlamına gelir ancak servo motor olan cer makinelerinde istisna olarak yoğunlaştırma işlemleri de yapılabilmektedir [3]. 
Çekim sisteminde birbirini takip eden alt ve üst silindirlerin kıstırma noktaları arasındaki mesafeye ekartman mesafesi denir. Ekartman mesafesi ortalama lif uzunluğuna göre ayarlanır (Şekil 1).

Ekartman ayarı, ortalama lif boyundan daha kisa ise uzun lif manşonlar üzerine sarabilecek veya kopacak, bu da düzgünsüzlük sorunlarına yol açacaktır. Ayrıca elyafların büyük kısmı hem ön hem de arka silindirlerce yakalanmış olacak ve materyalin düzgün çekimi sağlanmayacaktır.

Ekartman mesafesi ortalama lif boyundan daha fazla ise silindirler arasında çekim işlemi gerçekleşmeyecektir. Çünkü çekimin oluş şeklinde arka silindir lifi bırakacağı anda öndeki silindir lifi tutabilmelidir. Silindirler lifi bırakmadan önce lif hafifçe gerilebilmeli ve bu sayede lif çengel uçlarının açılabilmesi sağlanmış olmalıdır [3]. Ucu arka silindirlerce serbest bırakılmış kısa elyaflar, arka silindir hızında hareket edecek ve etrafinda uçları arka silindire tutulu elyaflar olacaktır. Yüzen ve arka silindire tutunan elyaflar arasındaki sürtünme nedeni ile yüzen elyaf arka silindirden aldı ̆̆ 1 hızı korursa çekim hatasız olur. Ancak ön silindire tutunan elyafların hızına kapılırsa gereğinden önce ön silindire gelecektir. Bunun sonucu ön silindirin kavraması gerekenden fazla elyaf kavranacaktır. Böylece ön silindir "iplikte kalın yer hatası" verecektir. Artık ön silindirde yüzen elyafı çekecek daha çok elyaf olacaktır. Bu esnada çekim bölgesinde yüzen elyaf sayısı azalacaktır. Arkada oluşan ince bölge ön silindire geldiğinde arka silindir hızına kapılan elyaf sayısı artacak ve "iplikte ince yer hatası" oluşacaktır.

Ekartman ayarında amaç; hem elyaf kırılmalarını en aza indirebilmek hem de ekartman mesafesinden daha kısa olan lifleri ve küçük partikülleri çekim kutusu içindeki üst ve alt hava emiş sistemleri aracılığı ile temizleyebilmektir.

Çalışma kapsamında, 2 farklı ekartman ayarı ile üretilen cer şeritleriyle elde edilen ipliklerin seçilmiş özelliklerinin kıyaslanması, buna bağlı olarak ekartman mesafesinin iplik kalite özelliklerine etkisinin ortaya konulması amaçlanmıştır.

\section{2. ÖNCEKİ ÇALIŞMALAR}

Buharalı ve Ömeroğlu [1] çalışmalarında hammadde özelliklerinin, hazırlık işlemlerinin ve eğirme parametrelerinin iplik kalite özelliklerine etkisini inceleyen yayınları derlemişlerdir. Jackowski ve arkadaşları [4] open-end rotor iplik eğirme makinesinde dört farklı numarada (3,5-4,04,5-5,0 ktex) ikinci pasaj cer şeridi kullanarak, her bir şeritten dört farklı numarada $(18,20,25$ ve 30 tex) olmak üzere on altı farklı rotor ipliği üretmişlerdir. Ardından bu ipliklerin mukavemet, uzama ve elastikiyet özellikleri incelenmiştir.

Farooq [5] çalışmasında, çeşitli cer çekim parametrelerinin (çıkış hızı, ara ve ana çekim mesafeleri, toplam çekim vb.) dinamik şerit kohezyonuna etkilerinin belirlenmesi amaçlanmıștır. Ayrıca yapay sinir ağları metoduyla dinamik şerit kohezyonunu tahminleme amaçlı model oluşturmuştur. Saha ve Hossen tarafindan yapılan çalışmada ring karde iplik kalitesi için cer makinasında dublajın optimizasyonu amaçlanmıştır. Ayrıca dublaj sayısının iplik kalitesine etkisi olup olmadığını ve 1 . ve 2 . Pasaj için uygun dublaj sayısı belirlenmeye çalışılmıştır [6]. Jabbar ve arkadaşları [7] çalışmalarında tarak ve cer makinasına ait bazı parametrelerin pamuk ipliği kalite özellikleri üzerindeki etkilerini belirlemeyi amaçlamışlardır. Sonuç olarak cer makinasında dublaj sayısı belirli bir değere kadar attıkça tüylülük, uzama ve mukavemetin arttığını belirlemişlerdir. Ayrıca tarak üretim hızı arttıkça düzgünsüzlüğün arttığını tespit etmişlerdir.

\section{MATERYAL VE METOT}

\subsection{Materyal}

Çalışma kapsamında cer makinası ekartman ayarlarının iplik kalite parametrelerine etkisi belirlenmeye çalışılmış olup, bu amaçla Gaziantep'te faaliyet gösteren SANKO Tekstil İşletmelerinde cer makinesinde ekartman ayarları dışında diğer tüm parametreler sabit tutularak şerit üretimleri gerçekleştirilmiştir. Cer makinası üretim parametreleri Çizelge 1'de her iki numune için verilmiştir. Ardından bu şeritlerle yine tüm üretim 
şartları ve ayarları sabit tutularak önce $\mathrm{Ne} 0,90$ numaralı fitil, ardından $\mathrm{Ne} 30$ numarada iplik üretilmiştir.

Çizelge 1. Cer üretim parametreleri

\begin{tabular}{|l|c|c|c|c|}
\hline & \multicolumn{2}{|c|}{ 1. PASAJ (SB 951) } & \multicolumn{2}{c|}{$\begin{array}{c}\text { 2. PASAJ (RSB } \\
\text { 951) }\end{array}$} \\
\hline & $\begin{array}{c}\text { Numune } \\
1\end{array}$ & $\begin{array}{c}\text { Numune } \\
2\end{array}$ & $\begin{array}{c}\text { Numune } \\
1\end{array}$ & $\begin{array}{c}\text { Numune } \\
2\end{array}$ \\
\hline $\begin{array}{l}\text { Ekartman } \\
\text { mesafesi } \\
\text { (mm) }\end{array}$ & $49-52$ & $43-48$ & $51-54$ & $43-50$ \\
\hline $\begin{array}{l}\text { Şerit Numaras1 } \\
\text { (Ne) }\end{array}$ & 0,120 & 0,120 & 0,120 & 0,120 \\
\hline $\begin{array}{l}\text { Ön Çekim } \\
\text { (inch) }\end{array}$ & 1,41 & 1,41 & 1,41 & 1,41 \\
\hline $\begin{array}{l}\text { Makine Devri } \\
\text { (dev/dak) }\end{array}$ & 550 & 550 & 450 & 450 \\
\hline \multicolumn{4}{|c|}{ Harman } & \multicolumn{3}{|c|}{ GAP Pamuğu (Şanliurfa Pamuğu) } \\
\hline
\end{tabular}

\subsection{Metot}

Farklı ekartman mesafelerinde üretilmiş cer şeritleriyle elde edilen ipliklere standartlara uygun olarak düzgünsüzlük, tüylülük ve mukavemet testleri uygulanmış ve elde edilen sonuçlar grafiksel olarak kıyaslanmıştır.

\section{- Düzgünsüzlük Testi}

İplikte düzgünsüzlük, uzunluk boyunca meydana gelen kütlesel değişimler olarak tanımlanabilmekte olup iplik kalitesini etkileyen en önemli faktörlerden biridir. İplikteki düzgünsüzlükler iplik mukavemetinin düşmesine, ince-kalın yerlerin oluşmasına ve bu ipliklerle üretilen kumaşların boyanmasında abraj hatalarının görülmesine sebep olmaktadır. İplik düzgünsüzlüğü hammadde özelliklerine bağlı olduğu gibi hammaddenin iplik oluncaya kadar geçirdiği proseslerde gördüğü işlemlerin kalitesine de bağlıdır.

Çalışma kapsamında düzgünsüzlük ve sık görülen hata tespiti testlerinin yapıldığ 1 Uster Tester-5, kapasitif sisteme (ipliğin, aralarında elektriksel alan oluşturulan iki kapasitif levha arasından geçirilerek kütlesel değişimlerden kaynaklanan elektriksel alan değişimlerinin belirlenmesi prensibine) göre çalışan, 400 metre/dakika hızla ölçüm yapabilen bir cihazdır. Test sonucunda iplik yapısındaki bütün düzgünsüzlük değerlerini, standart sapmaları, tüylülük, ince-kalın yer gibi birçok parametreyi sayısal olarak sunmaktadır.

İplik düzgünsüzlügüün sayısal olarak ifade edilmesi için değişim katsayısı (Coefficient of Variation, \%CV) veya ortalama mutlak sapma (Unevenness, \%U) ifadeleri kullanılmaktadır. Ortalama mutlak sapma, gerek kesikli lif ipliklerinin gerekse filament ipliklerin düzgünsüzlüğünün belirlenmesinde kullanılan ilk istatistiksel ölçüdür. Ancak, bugün tekstil endüstrisinde her türlü değişim için genellikle değişim katsayısı kullanılmaktadır. Düzgünsüzlüğün ifade edilmesi için de gelecekte sadece değişim katsayısının kullanılması tavsiye edilmektedir [8].

\section{- Tüylülük Testi}

İplik tüylülüğü, genel olarak birim uzunluk veya alan başına iplik yüzeyinden dışarı çıkan liflerin sayısı ya da iplik yüzeyine dik olarak ölçülen lif uzunluğu olarak tanımlanmaktadır.

Son yıllarda iplik tüylülüğü; iplik numarası, mukavemeti ve düzgünsüzlüğü gibi önemli kalite parametrelerinden birisi olarak kabul edilmekte olup, bazı özel durumlar hariç genel anlamda istenilmeyen bir özelliktir. İplik tüylülüğünün kabul edilebilir bir sınırın üzerinde olması, iplik üretimi sırasında uçuntu oluşumu, çözgü çekme ve dokuma işlemleri sırasında yan yana gelen lif uçlarının düğümlenmesi sonucu kopuş vb. problemlere sebep olmaktadır. Ayrıca iplik tüylülüğü, kumaşlarda boncuklanma gibi bazı problemleri olumsuz etkilemekte, boya-terbiye ve bitim işlemlerinden sonra görünüm bozukluklarına yol açmaktadır. $\mathrm{Bu}$ nedenle iplik tüylülüğünün kabul edilebilir sınırları aşıp aşmadığının henüz üretim aşamasında tespit edilmesi, önlemeye veya azaltmaya yönelik önlemlerin kısa sürede alınması bakımından önemlidir [9].

Cer pasaj sayısı arttıkça bant içindeki lif kancaları açılmakta, dolayısıyla bant içindeki liflerin uzunluğu artmakta ve buna bağlı olarak iplik 
tüylülüğü azalmaktadır. Cer bandından direkt olarak iplik eğirmek iplik tüylülüğünü arttırmaktadır [10]. Cer makinasında ekartman mesafesinin kısa tutulması halinde de yüzen elyaf daha az olacağından daha yoğun ve düzgün şeritler elde edileceği ve tüylülük derecesinin düşeceği düşünülmektedir.

İplik tüylülüğünü hassas ve doğru bir şekilde tespit etmeye yönelik çok sayıda yöntem ve cihaz geliştirilmiş olmakla birlikte, bu yöntemlerin çok azı pratikte uygulama alanı bulabilmiştir. Günümüzde en yaygın olarak kullanılan yöntem fotoelektrik ölçüm yöntemi olup, yaygın olarak kullanılan test cihazları ise UT3 veya UT4 (Uster), Pt7000 (Premier), G 565 ve G 566 (Zweigle) gibi cihazlardır.

Çalışma kapsamında ipliklerinin tüylülük dereceleri USTER Tester ve Uster Zweigle cihazlarında test edilmiştir.

Zweigle G 565 ve G 566 cihazlarında ölçüm sırasında iplik, bir 1şık kaynağından iplik eksenine dik olarak gönderilen 1 şık hüzmesi tarafından yoklanır. İplik ve iplik gövdesinden çıkan lifler, ölçüm bölgesine gönderilen 1şık demetini keser ve gönderilen ışınların ölçülebilen parlaklığında dalgalanmaya sebep olur. $\mathrm{Bu}$ şekilde iplik gövdesinden çıkan lifler tarafından engellenen 1 şık demeti, düştüğü fototransistör üzerinde bir fotoakıma dönüştürülür ve kuvvetlendirilerek değerlendirilir. Tek bir geçişte iplik 12 ayrı fototransistör tarafindan taranır ve iplik yüzeyinden çıkan lifler 1-25 mm arasında değişen 12 farklı uzunluk bölgesinde gruplandırılır. Test sonucunda Zweigle G 566 test cihazından tüylülük indeksi $\left(\mathrm{H}_{\mathrm{Z}}\right)$ ile birlikte $\mathrm{S}_{3}$ değeri (3 $\mathrm{mm}$ ve daha uzun olan tüylerin sayısı), Tp (toplam tüy sayısı) ve her bir uzunluk sınıfındaki tüy sayısı alınabilmektedir. Cihaz $50 \mathrm{~m} /$ dak hızla ölçüm yapmakta ve ölçüm uzunluğu 10-9999 m arasında değişebilmektedir [9].

Uster Tester cihazında ise bir 1şık kaynağından çıkan ışık optik sistem yardımıyla kırılarak ölçüm alanına yerleştirilmiş olan iplik üzerine gönderilir ve iplik yüzeyinden dışarıya doğru çıkmış lifler tarafından dağıtılan 1 şık, optik sistem tarafından toplanarak alıcı üzerine düşürülür. Cihazda, $1 \mathrm{~cm}$ uzunluğundaki iplik yüzeyinde çıkıntı halindeki liflerin uzunluğu toplamının, birim iplik uzunluğuna $(1 \mathrm{~cm})$ oranı tüylülük indeksi $\left(\mathrm{H}_{\mathrm{U}}\right)$ olarak hesaplanır [9].

\section{- Mukavemet Testi}

İplikler, sonraki işlemlerde duraklama veya kesintiye sebep olmamak için yeterince mukavemetli olmalıdır. Bugün piyasada en çok kabul gören cihazlar CRE (Sabit uzama hızı) prensibine göre çalışan cihazlardır. Uster Tensojet ve Uster Tensorapid test cihazları da bu prensibe göre çalışmaktadırlar. İki cihaz prensipte birtakım farklılıklara sahiptirler. Çalışma kapsamında iplik mukavemet testlerinde Uster ${ }^{\circledR}$ Tensojet 4 cihazı kullanılmıştır. Bu cihaz ile ölçülen büyüklükler aşağıda kısaca tanımlanmıştır [11]:

- Kopma kuvveti (B-Kuvvet): Bir ipliği koparmak için uygulanması gereken kuvvet değeridir. Birimi gF'dir.

- Kopma uzaması: İpliğe uygulanan kuvvet altında kopma mukavemetine kadar ipliğin ne kadar uzayabildiğinin ölçüsüdür. \% değeri ile ifade edilir.

- Mukavemet (Sağlamlık): Uster tarafindan kullanılan mukavemet değeri iplik üzerinde bulunan maksimum kuvvet belirler (kopma noktasına kadar) ve iplik numarasını referans alarak bir değer oluşturmaktadır. Birimi N/tex'dir. (RKM; 0,9807 cN/tex)

- Kopma işi (B-iş): İpliğe maksimum koşullarda etki eden kuvvet ile ipliğin bu kuvvet etkisiyle yer değiştirme mesafesinin çarpımına eşittir. Birimi cN.cm'dir.

\section{BULGULAR}

\subsection{Düzgünsüzlük Test Sonuçları}

Çalışma kapsamında yapılan deneysel çalışma sonucu elde edilen, numunelere ait düzgünsüzlük test sonuçları toplu olarak Çizelge 2'de verilmiştir. İki numunenin $\% \mathrm{U}$ ve $\% \mathrm{CVm}$ değerlerindeki değişimin grafiksel gösterimi ise Şekil 2'de görülmektedir. 
Çizelge 2. Düzgünsüzlük test sonuçları

\begin{tabular}{|l|c|c|}
\hline & Numune 1 & Numune 2 \\
\hline$\% \mathrm{U}$ & 19,1 & 14,3 \\
\hline $\begin{array}{l}\text { İnce yer } / \mathrm{km} \\
(-40 \%)\end{array}$ & 1854,17 \\
\hline $\begin{array}{l}\text { İnce yer / km } \\
(-50 \%)\end{array}$ & 165,0 & 286 \\
\hline $\begin{array}{l}\text { Kalın yer / km } \\
(+35 \%)\end{array}$ & 787,5 & 1444 \\
\hline $\begin{array}{l}\text { Kalın yer / km } \\
(+50 \%)\end{array}$ & 117 & 278,5 \\
\hline $\begin{array}{l}\text { Neps / km } \\
(+140 \%)\end{array}$ & 225,5 & 350,5 \\
\hline $\begin{array}{l}\text { Neps / km } \\
(+200 \%)\end{array}$ & 21,5 & 32,5 \\
\hline
\end{tabular}

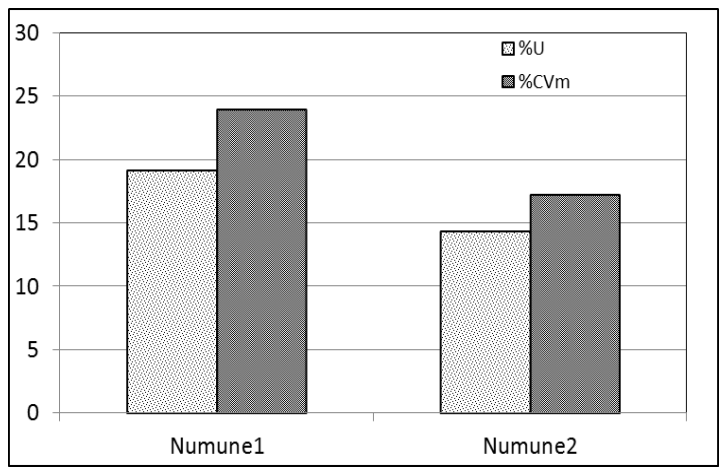

Şekil 2. Düzgünsüzlük test sonuçları

Elde edilen test sonuçlarına göre; 1. numunenin (ekartman mesafesi iki pasajda da fazla olan numune) $\mathrm{U}$ ve $\mathrm{CV}_{\mathrm{m}}$ değerlerinin 2 nolu numuneden sirasiyla $\% 25$ ve $\% 28$ oranlarında yüksek çıktığı, başka bir ifadeyle 1 nolu numunenin düzgünsüzlüğünün daha fazla olduğu görülmektedir. $\mathrm{Bu}$ durumun beklenen şekilde 1 . numunede silindirler arası mesafenin fazla olmasından kaynaklandığı söylenebilmektedir.

Düzgünsüzlük testi sırasında ölçülen periyodik hata değerlerinden ise $-\% 40,-\% 50$ ince yer, $+\% 35$, $+\% 50$ kalın yer, $+\% 140,+\% 200$ neps değerleri ele alınmış olup ekartman mesafesi artışı ile ince yer sayısının arttığı, ancak kalın yer ve neps sayılarının azaldığı görülmüştür. İnce yer miktarlarındaki artışın kalın yer ve neps değişimlerinden oldukça fazla bir oranda gerçekleştiği tespit edilmiştir. $\mathrm{Bu}$ durumda sık rastlanan hatalar açısından da ekartman mesafesinin fazla olmasının olumsuz kalite değerlerine yol açtığı söylenebilmektedir.

\subsection{Tüylülük Test Sonuçları}

Uster Tester ve Zweigle test cihazları ile yapılan tüylülük test sonuçları her iki numune için toplu olarak Çizelge 3'de verilmiştir.

Çizelge 3. Tüylülük test sonuçları

\begin{tabular}{|c|c|c|}
\hline & Numune $\mathbf{~}$ & Numune 2 \\
\hline $\mathbf{1} \mathbf{~ m m}$ & 28626 & 30174 \\
\hline $\mathbf{2} \mathbf{~ m m}$ & 7604 & 7374 \\
\hline $\mathbf{3} \mathbf{~ m m}$ & 2039 & 1669 \\
\hline $\mathbf{4} \mathbf{~ m m}$ & 753 & 821 \\
\hline $\mathbf{6} \mathbf{~ m m}$ & 115 & 157 \\
\hline $\mathbf{8} \mathbf{~ m m}$ & 18 & 22 \\
\hline $\mathbf{1 0} \mathbf{~ m m}$ & 3 & 6 \\
\hline $\mathbf{S}_{\mathbf{1 + 2}}$ & 36230 & 37648 \\
\hline $\mathbf{S}_{\mathbf{3}}$ & $\mathbf{2 9 2 8}$ & $\mathbf{2 6 7 5}$ \\
\hline $\mathbf{H}_{\mathbf{u}}$ & $\mathbf{9 , 4 2}$ & $\mathbf{8 , 4 3}$ \\
\hline
\end{tabular}

$\mathrm{S}_{3}: 3 \mathrm{~mm}$ ve daha uzun olan tüylerin sayısıdır.

$\mathrm{H}_{\mathrm{u}}$ : İpliğin yapısından dışarı çıkan liflerin toplam uzunluğunun ipliğin $1 \mathrm{~cm}$ 'sine oranıdır.

Test sonuçlarına bakıldığında $1,2,3,4,6,8$ ve $10 \mathrm{~mm}$ uzunluktaki tüy sayılarının değişkenlik gösterdiği, bazı uzunluklarda (2 $\mathrm{mm}$ ve $3 \mathrm{~mm}$ ) Numune 1'in, bazı uzunluklarda $(1,4,6,8$ ve 10 $\mathrm{mm})$ Numune 2'nin tüy miktarının yüksek olduğu görülmektedir. Ancak $\mathrm{S}_{3}$ ve $\mathrm{H}_{\mathrm{u}}$ değerlerine bakıldığında, ekartman mesafesinin daha kısa tutulduğu Numune 2'de bu iki büyüklük için daha düşük değerler elde edildiği belirlenmiştir (Şekil 3). Başka bir ifadeyle ekartman mesafesi düşürülünce tüylülük değerleri azalmıştır. $\mathrm{S}_{3}$ değerindeki düşüş yaklaşı $\% 9$ oranında gerçekleşmiştir.

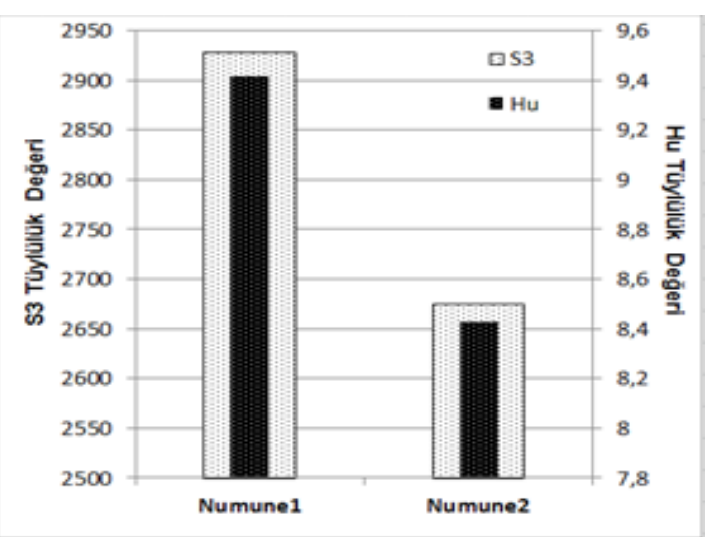

Şekil 3. Tüylülük test sonuçları 


\subsection{Mukavemet Test Sonuçları}

Numunelere ait mukavemet test sonuçları Çizelge 4'te, \% uzama ve mukavemet sonuçlarının grafiksel gösterimi ise Şekil 4'te verilmiştir. Sonuçlardan görüldüğü gibi ekartman mesafesinin azaltılması durumunda mukavemet değerlerinde bir miktar artış (yaklaşık \%9) meydana gelmiştir. $\mathrm{Bu}$ durumun çalışmada ele alınan hammadde için ekartman mesafesinin daha kısa olması durumunda yüzen elyaf miktarının azalmasından ve liflerin iplik içerisine daha fazla katılmasından kaynaklandığı düşünülmektedir.

Çizelge 4. Mukavemet testi sonuçları

\begin{tabular}{|l|c|c|}
\hline & Numune 1 & Numune 2 \\
\hline B-Kuvvet (cN) & 1580 & 1711 \\
\hline Uzama (\%) & 6,34 & 6,8 \\
\hline Mukavemet (cN/Tex) & 18,72 & 20,33 \\
\hline B-İș (cN.cm) & 2473 & 2516 \\
\hline
\end{tabular}

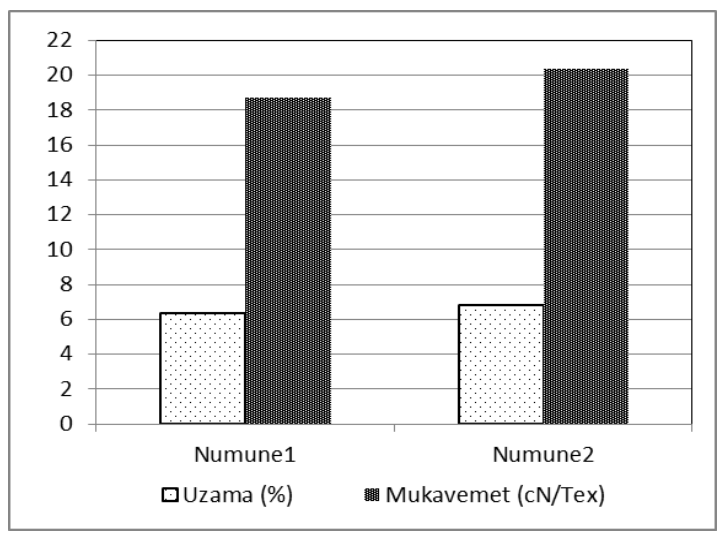

Şekil 4. Mukavemet test sonuçları

\section{SONUÇLAR}

Cer makinasında ekartman ayarlarında yapılan değişikliğin seçilmiş iplik özelliklerine etkisinin araştırıldığı çalışma kapsamında elde edilen sonuçlar aşağıda özetlenmiştir.

1. Cer makinasında ekartman mesafesinin artırılması düzgünsüzlük değerlerinde $(\% \mathrm{U}$ ve $\% \mathrm{CVm}$ ) artışa neden olmuştur. $\mathrm{Bu}$ durumun çalışma kapsamında kullanılan pamuk lif uzunluğuna bağlı olarak uzun ekartman mesafesinde yüzen lif miktarının artmasından kaynaklandığ 1 düşünülmektedir.

2. Düzgünsüzlük sonuçlarına benzer şekilde tüylülük değerlerinde de uzun ekartman mesafesinde daha yüksek tüylülük değerleri elde edilmiştir.

3. Ekartman mesafesinin her iki pasaj cerde de daha yüksek tutulduğu 1 nolu numunenin mukavemet ve uzama değerlerinin de diğer numuneye göre bir miktar düşük çıktığ1 görülmüştür.

$\mathrm{Bu}$ durumda çalışmada numune olarak seçilen Şanlıurfa GAP pamuğu için Numune 2'nin cer üretim şartlarının (daha kısa ekartman mesafesi) iplik kalite parametreleri açısından daha olumlu sonuçlar doğurduğu ve ekartman mesafesinin artış1 ile iplik düzgünsüzlük, tüylülük değerlerinin arttığı, mukavemetin bir miktar düştüğü tespit edilmiştir.

\section{TEŞEKKÜR}

Çalışmada kullanılan ipliklerin üretimi ve testlerin gerçekleştirilmesi hususunda gösterdikleri yardımlar için Gaziantep SANKO Tekstil İşletmelerine teşekkür ederiz.

\section{KAYNAKLAR}

1. Buharalı, G., Ömeroğlu, S., 2013. Open-End Rotor İplik Özelliklerine Etki Eden Faktörler, Uludağ Üniversitesi Mühendislik-Mimarlık Fakültesi Dergisi, Cilt 18, Say1 2, 19-36.

2. Klein, W., 2011. Rieter İplikçilik El Kitabı-Cilt 3, Rieter Machine Works Ltd. (Tercüme: Prof. Dr. H. Erhan Kirtay).

3. Tekstil Teknolojisi- Cer Makinesi, Milli Eğitim Bakanlığı Yayınları, http://megep.meb.gov.tr/ mte_program_modul/moduller_pdf/Cer\%20Ma kinesi.pdf, Ankara, 2011.

4. Jackowski, T., Chylewska, B., Cyniak, D., 2002. Influence of the Spinning Process Parameters on Strength Characteristics of Cotton Yarns, Fibres\&Textiles in Eastern Europe, Vol: 38, 27-31, July/September. 
5. Farooq, A., 2014. Predicting the Dynamic Cohesion in Drafted Slivers at Draw Frame Using Artificial Neural Networks, Tekstil ve Konfeksiyon Dergisi, 24(3), 286-290.

6. Saha, A. S. K., Hossen, B. J., 2011. Optimization of Doubling at Draw Frame for Quality of Carded Ring Yarn, International Journal of Engineering \& Technology IJETIJENS Vol: 11 No: 06, 75-80.

7. Jabbar, A., Hussain, T., Moqeet A., 2013. Impact of Carding Parameters and Draw Frame Doubling on the Properties of Ring Spun Yarn, Journal of Engineered Fibers and Fabrics, Vol:8 (2), 72-78

8. Kılıç, M., 2010. Karışım İpliklerinde Düzgünsüzlük ve Tüylülük Analizleri, Dokuz Eylül Üniversitesi Fen Bilimleri Enstitüsü, Tekstil Mühendisliği ABD, Doktora Tezi.

9. Alay, S., Göktepe, F., 2006. Farklı İplik Tüylülüğü Test Cihazlarından Elde Edilen Sonuçların Karşılaştırılması, Süleyman Demirel Üniversitesi, Fen Bilimleri Enstitüsü Dergisi, 10-3, 422-427.

10. Can, Y., Kırtay, E., 2003. Pamuk İpliklerinde İplik Tüylülüğü ve Tüylülüğe Etki Eden Faktörler (Kaynak Taramas1), Mühendislik Bilimleri Dergisi, 9 (3), 379-385.

11. Soyaslan, D., 2009. Uster Tensojet ve Tensorapid Test Cihazlarının Test Parametreleri ve Çalışma Prensiplerinin Karşılaştırılması, Tekstil Teknolojileri Elektronik Dergisi, Cilt: 3, No: 1, 71-75. 